\title{
ASPEK REPRODUKSI IKAN KERAPU SUNU (Plectropomus leopardus) DI PERAIRAN SULAWESI DAN MALUKU
}

\begin{abstract}
RetnoAndamari
ABSTRAK

Penelitian aspek reproduksi ikan kerapu sunu Plectropomus leopardus telah dilaksanakan dalam rangka menunjang usaha perbenihan. Sampling dilakukan pada bulan Maret, April, dan September 2004 di Teluk Piru (Maluku Tengah), Manado (Sulawesi Utara), Gorontalo, dan P. Bacan (Maluku Utara). Ikan kerapu sunu yang diperoleh sebanyak 121 ekor terdiri atas 82 ekor ikan betina, 27 ekor ikan jantan, 9 ekor hermaprodit, dan 3 ekor tidak dapat diidentifikasi. Hubungan panjang $(L)$ dan bobot $(W)$ didekati melalui fungsi $W=a L^{\circ}$. Berdasarkan data sampel dengan selang kepercayaan 95\% nilai b dapat diterima sama dengan 3 (tiga) sehingga dapat disimpulkan bahwa ikan kerapu sunu dari perairan Sulawesi dan Maluku mempunyai sifat pertumbuhan isometrik. Hasil pengamatan terhadap tingkat kematangan gonad menunjukkan bahwa sebanyak 70 ekor $(85 \%)$ ikan betina baru mulai berkembang dan hanya terdapat 12 ekor (15\%) ikan betina yang matang gonad dengan jumlah fekunditas berkisar 45.768 butir sampai 492.243 butir dengan rata-rata 112.142. Nilai Indeks Kematangan gonad (IKG) berkisar antara 0,10-3,23.
\end{abstract}

ABSTRACT: Study on biological reproduction of leopard coral grouper (Plectropomus leopardus) from Sulawesi and Maluku waters, by: Retno Andamari

Study on reproduction aspects of leopard coral grouper (Plectropomus leopardus) has carried out in order to support breeding and seed production. Fish sample collected were from Piru Bay (Central Maluku), North Sulawesi, Gorontalo, and Bacan Island (North Maluku) in March, April, and September 2004. The results shown that from 121 fish samples, which of 82 ind. were female, 27 ind. were male, 9 ind. hermaphrodites, and 3 ind. unidentified. Gonad maturation of fish sample has been observed and from 70 individual (85\%) female fish had initial development gonad and 12 individual (15\%) of female fish had complete mature gonad. Length-weight relationship with $95 \%$ confidence interval has a " $b$ " value 3 (three) meaning that leopard coral grouper has an isometric growth. The fecundity was 45,768 oocytes to 492,243 oocytes with the average of 112,142 oocytes. The GSI ranged from 0.10 to 3.23 .

KEYWORDS: $\quad$ reproduction, GSI, grouper, Plectropomus leopardus

\section{PENDAHUL.UAN}

Ikan kerapu sunu (Plectropomus leopardus) merupakan jenis ikan laut yang mempunyai pasar luas dengan harga yang relatif tinggi dan diekspor dalam keadaan hidup ke luar negeri seperti Singapura, Hongkong, Taiwan, dan China Selatan (Chou \& Lee, 1998). Pada saat ini harga ikan kerapu sunu hidup di tingkat pedagang pengumpul di Denpasar, Bali mencapai Rp 300.000,-/kg. Data ekspor ikan kerapu, termasuk kerapu sunu, yang tercatat di Laboratorium Pembinaan dan Pengujian Mutu Hasil Perikanan Provinsi Bali tahun 2003 menunjukkan lebih dari 2,8 ton/tahun (Anonymous, 2004). Ikan kerapu tersebut, termasuk kerapu sunu, sebagian besar ( $82 \%$ ) diekspor ke Taiwan dan sebagian kecil (18\%) diekspor ke berbagai negara, khususnya di Asia Tenggara. Ikan kerapu hidup yang diperjualbelikan saat ini pada umumnya berasal dari penangkapan di alam yang diperkirakan tidak memperhatikan kaidah hasil tangkapan lestari. Apabila penangkapan di alam dilakukan terus-menerus tanpa memperhatikan aspek reproduksi seperti ukuran ikan dan musim pemijahan maka di-khawatirkan akan terjadi tangkap-lebih yang mengakibatkan terganggunya kontinuitas ketersediaan ikan kerapu dari alam. Dalam upaya merintis kearah perbenihan kerapu sunu, maka informasi aspek reproduksi ikan tersebut perlu mendapat perhatian.

Budi daya kerapu sunu hingga kini masih belum berkembang. Penyediaan benih masih mengandalkan pasok benih dari alam dan sangat tergantung pada musim. Dengan meningkatnya kebutuhan benih kerapu sunu untuk budi daya, maka perlu dilakukan usaha pembenihan secara terkontrol dalam rangka penyediaan benih yang berkesinambungan.

Untuk pemecahan masalah penyediaan benih tersebut, maka langkah pertama yang harus dilakukan

Peneliti pada Balai Besar Riset Perikanan Budidaya Laut, Gondol 
adalah melalui upaya penelusuran karakteristik biologi ikan kerapu sunu, di antaranya penelaahan hubungan panjang-berat terhadap tingkat kematangan gonad, ukuran perubahan jenis kelamin, fekunditas, dan indeks kematangan gonad sehingga diharapkan dapat mendukung percepatan sistem perbenihan.

\section{BAHAN DAN METODE}

\section{Sampling}

Pada tahun 2004 berbagai macam ukuran ikan kerapu sunu Plectropomus leopardus (Gambar 1) diambil dari lokasi Perairan Sulawesi Utara (Manado), Gorontalo, Teluk Piru (Maluku Tengah), dan P. Bacan (Maluku Utara) (Gambar 2). Ikan sampel diukur panjang dan bobotnya, selanjutnya gonad diambil dan diawetkan dengan formalin $10 \%$ dan dibawa ke laboratorium penelitian Balai Besar Riset Perikanan Budidaya Laut, Gondol untuk diproses lebih lanjut.

\section{Analisis Laboratorium}

Gonad dikering-udarakan, ditimbang, dan dibuat preparat histologi (Luna, 1968) untuk menentukan tingkat kematangan (Andamari et al., 1998) dan perubahan kelaminnya (sex reversal). Untuk membuat preparat histologi gonad diambil sebagian dan diawetkan dalam formalin minimum24 jam, kemudian dicuci dan direndam dalam alkohol. Gonad tersebut kemudian dilakukan penjernihan dengan cara merendam dalam larutan alkohol secara bertingkat dan selanjutnya direndam dalam xylene untuk menghilangkan kadar air yang terdapat di dalam jaringan gonad. Setelah itu gonad dilakukan perendaman dalam parafin dan dilakukan pengirisan dengan mikrotome setebal $6 \mu$. Irisan tersebut kemudian diberi pewarna hematoxylen dan eosin. Selanjutnya irisan gonad siap untuk dibaca. Gonad yang telah matang diambil sebagian untuk menentukan fekunditas per angkatan (batch fecundity) dan diameter oosit.
Hubungan panjang berat dihitung dengan rumus: $\mathrm{W}=\mathrm{aL}^{\mathrm{b}}$ (Royce, 1984) di mana $\mathrm{W}=$ berat $(\mathrm{g}) ; \mathrm{L}=$ panjang $(\mathrm{cm})$, a dan b konstanta. Tingkat kematangan gonad ditentukan dengan memakai kriteria enam tingkatan sesuai dengan klasifikasi Hunter \& Goldberg (1980), Cyrus \& Blaber (1984), Effendi (1997), Andamari et al. (2003).

Setelah diketahui tingkat kematangannya, selanjutnya gonad yang telah matang diambil sebagian untuk digunakan sebagai bahan pendugaan jumlah telur per angkatan (fekunditas). Pendugaan ini berdasarkan rumus Bagenal (1978) yaitu: $F=(\mathrm{Wg} /$ Ws)n di mana: $\mathrm{F}=$ batch fecundity; $\mathrm{Wg}=$ berat gonad (g); Ws= berat sub sampel ( $\mathrm{g}$ ); $\mathrm{n}=$ jumlah telur dalam sub sampel.

\section{HASIL DAN BAHASAN}

Deskripsi panjang dan bobot kerapu sunu yang disampling dari perairan Maluku Tengah (Teluk Piru), Sulawesi Utara (Manado), Gorontalo, dan P. Bacan (Maluku Utara) disajikan pada Tabel 1.

Pada Tabel 1 terlihat bahwa ukuran panjang standar ikan kerapu sunu yang terkecil dan terpanjang masing-masing adalah $185 \mathrm{~mm}$ dan $437 \mathrm{~mm}$, sedangkan bobot terkecil dan terbesar masing-masing $230 \mathrm{~g}$ dan $2.750 \mathrm{~g}$. Hubungan panjang bobot ikan kerapu sunu diperlihatkan pada Gambar 3. Pada hubungan ini diperoleh nilai $b=3$ berdasarkan selang kepercayaan $95 \%$ dan nilai b tersebut sebesar(2.915, 3.187 ) yang berarti bahwa pertumbuhan ikan kerapu sunu bersifat isometrik yakni pertumbuhan bobotnya seimbang dengan panjang pangkat tiga ikan tersebut. Dalam penelitian ikan kerapu sunu pada lokasi yang berbeda diperoleh bahwa nilai b lebih besar dari 3 (tiga) yakni pertumbuhan bersifat allometrik (Andamari et al., 2004; Andamari et al., 2005).

Pada spesies yang sama bisa saja terjadi perbedaan nilai "b" pada hubungan panjang bobot yang disebabkan oleh beberapa faktor di antaranya jumlah sampel yang dianalisis, variasi ukuran ikan sample,

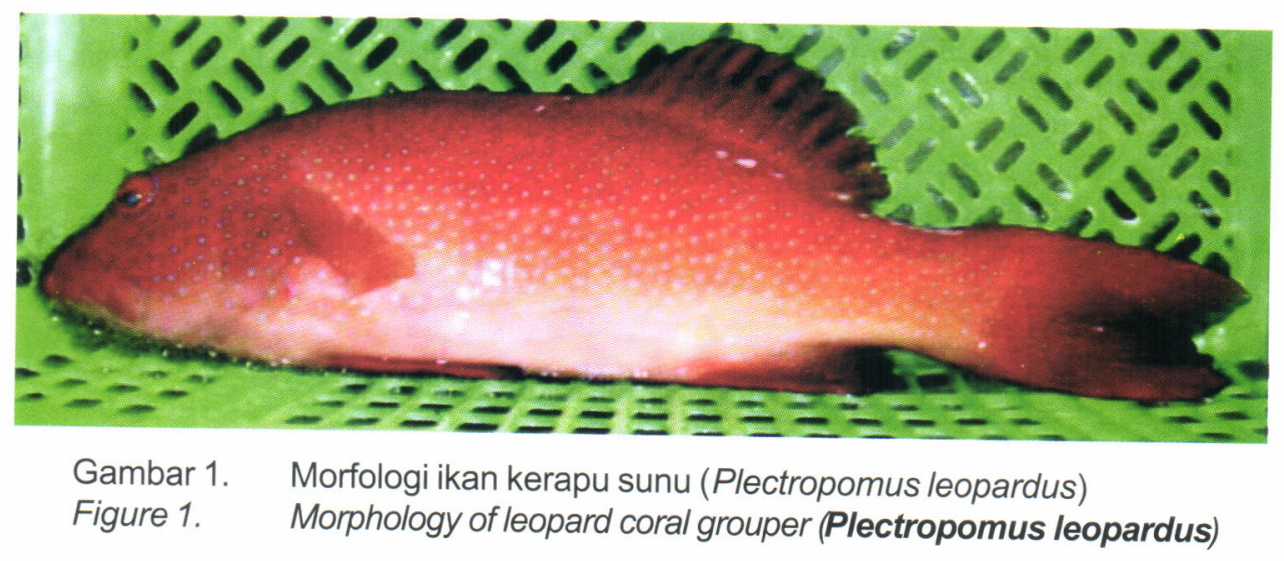


Tabel 1. Deskripsi panjang dan bobot kerapu sunu P. leopardus di perairan Sulawesi dan Maluku

Table 1. Standard length and weight description of leopard coral grouperP. leopardus from Sulawesi and Maluku waters

\begin{tabular}{|c|c|c|c|c|c|c|c|c|}
\hline \multirow{2}{*}{$\begin{array}{l}\text { Lokasi } \\
\qquad \text { Locations }\end{array}$} & \multirow{2}{*}{$\begin{array}{l}\text { Bulan } \\
\text { Month (2004) }\end{array}$} & \multirow{2}{*}{$\mathbf{n}$} & \multicolumn{3}{|c|}{ Panjang (Length) (mm) } & \multicolumn{3}{|c|}{ Bobot (Weight) (g) } \\
\hline & & & Min & Max & Mean \pm SD & Min & Max & Mean \pm SD \\
\hline Maluku & Maret & 30 & 221 & 437 & $333.7 \pm 7.013$ & 300 & 2,750 & $1249 \pm 773.928$ \\
\hline Manado & April & 26 & 210 & 428 & $309.1 \pm 5.705$ & 300 & 2,525 & $1014.73 \pm 605.043$ \\
\hline Gorontalo & April & 7 & 260 & 321 & $296 \pm 2.147$ & 575 & 825 & $726.43 \pm 95.817$ \\
\hline Maluku Utara & September & 35 & 185 & 430 & $299.5 \pm 6.844$ & 230 & 2,475 & $946.57 \pm 605.954$ \\
\hline Gorontalo & September & 23 & 225 & 420 & $315 \pm 5.763$ & 300 & 2,125 & $969.6 \pm 522.344$ \\
\hline \multicolumn{2}{|c|}{ Jumlah } & 121 & 185 & 437 & $312.9 \pm 6.33$ & 230 & 2,750 & $1027.83 \pm 629.025$ \\
\hline
\end{tabular}

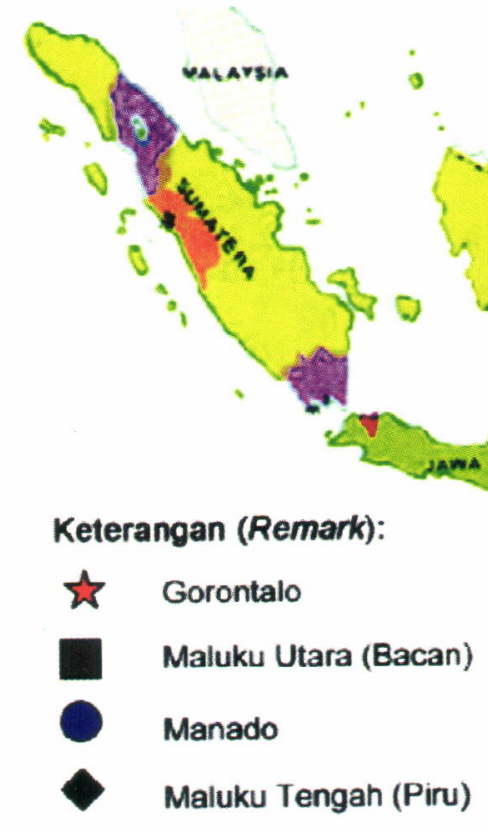

Gambar 2. Lokasi pengambilan sampel ikan kerapu sunu Peopardus di perairan Sulawesi dan Maluku, 2004 Figure 2. Sampling location of leopard coral grouper in Sulawesi and Maluku waters, 2004

serta waktu (musim). Pada umumnya nilai "b" berkisar antara 2 sampai 3,5 (Royce, 1984).

\section{Tingkat Kematangan Gonad}

Hasil pengamatan histologi gonad kerapu sunu dengan jumlah 121 ekor menunjukkan bahwa sebagian besar $(68 \%)$ ikan kerapu sunu berjenis kelamin betina dengan tingkat perkembangan gonad awal (Tingkat I). Ikan kerapu sunu yang terkecil dan sudah dapat diidentifikasi sebagai ikan betina (gonad mulai berkembang) berukuran panjang standar 205 $\mathrm{mm}$ dan bobot $260 \mathrm{~g}$. Dari sampel, terlihat pula bahwa jumlah ikan betina lebih banyak dibandingkan dengan jumlah ikan jantan ataupun ikan yang hermaprodit. Hal ini sejalan pula dengan penelitian yang telah dilakukan sebelumnya di berbagai lokasi (Andamari et al., 2004; Andamari et al., 2005) Ikan kerapu sunu termasuk jenis ikan hermaprodit protogini yaitu berubah kelamin dari betina menjadi jantan pada ukuran tertentu (Tabel 2). Pergantian kelamin (sex reversal) tidak dapat ditentukan secara visual karena dari pengamatan gonad secara histologis ikan kerapu sunu pada ukuran yang sama dapat berjenis kelamin betina, jantan ataupun hermaprodit. Untuk usaha perbenihan, perlu diperhatikan penyediaan induk jantan dan betina yang sebanding, yakni ikan-ikan 
yang berbobot lebih dari $2 \mathrm{~kg}$ untuk ikan jantan dengan asumsi ikan-ikan tersebut sudah berubah kelamin menjadi jantan sedangkan untuk induk betina berbobot antara 1 sampai $1,5 \mathrm{~kg}$

\section{Indeks Kematangan Gonad}

Salah satu ukuran untuk menentukan tingkat kematangan gonad adalah Indeks Kematangan Gonad (IKG). Hal ini diterapkan bila tidak dilakukan pengamatan gonad secara histologi. Di dalam penelitian ini selain diamati secara histologi tetapi dilakukan juga penghitungan indeks kematangan gonad untuk lebih memperjelas adanya hubungan indeks kematangan gonad dengan tingkat kematangan gonad. Hubungan antara IKG terhadap berat ikan serta IKG terhadap panjang ikan dapat dilihat pada Gambar 3 dan 4. Dari kedua hubungan ini terlihat bahwa ikan- ikan yang lebih panjang dan lebih berat tidak selalu mempunyai nilai IKG yang tinggi. Nilai IKG lebih ditentukan oleh tingkat kematangan gonadnya. Ukuran ikan yang lebih kecil tetapi berada pada kondisi tingkat kematangan gonad yang sudah lanjut (TKG V) akan mempunyai nilai IKG yang lebih tinggi. Ikan kerapu sunu pada penelitian ini termasuk dalam kategori matang gonad apabila mempunyai nilai IKG lebih besar dari 1,5 .

\section{Fekunditas}

Hasil pengamatan terhadap fekunditas telur kerapu sunu menunjukkan kisaran antara 45.768 butir hingga 492.243 butir dengan rata-rata 112.142 oocytes (Tabel 3). Diameter oosit berkisar antara $450-500 \mu$. Pada saat memijah (setelah oosit bersifat planktonis) 00cytes kurang lebih berdiameter $800 \mu$. Kerapu sunu

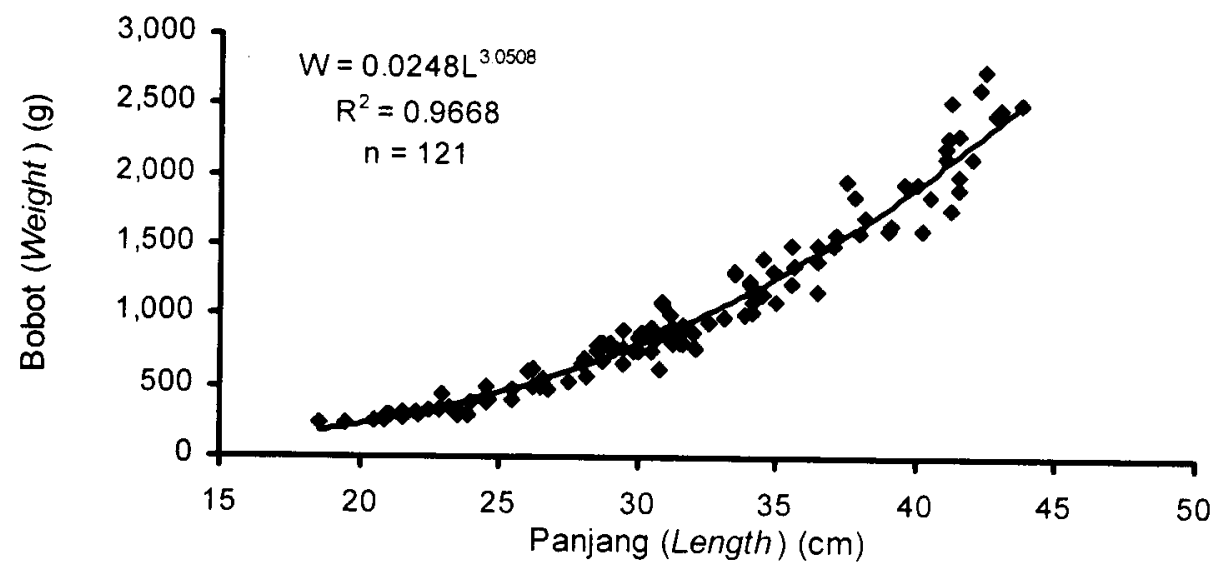

Gambar 3. Hubungan panjang bobot ikan kerapu sunu dari berbagai perairan di Sulawesi dan Maluku Figure 3. Length-weight relationship of P. leopardus from several waters in Sulawesi and Maluku

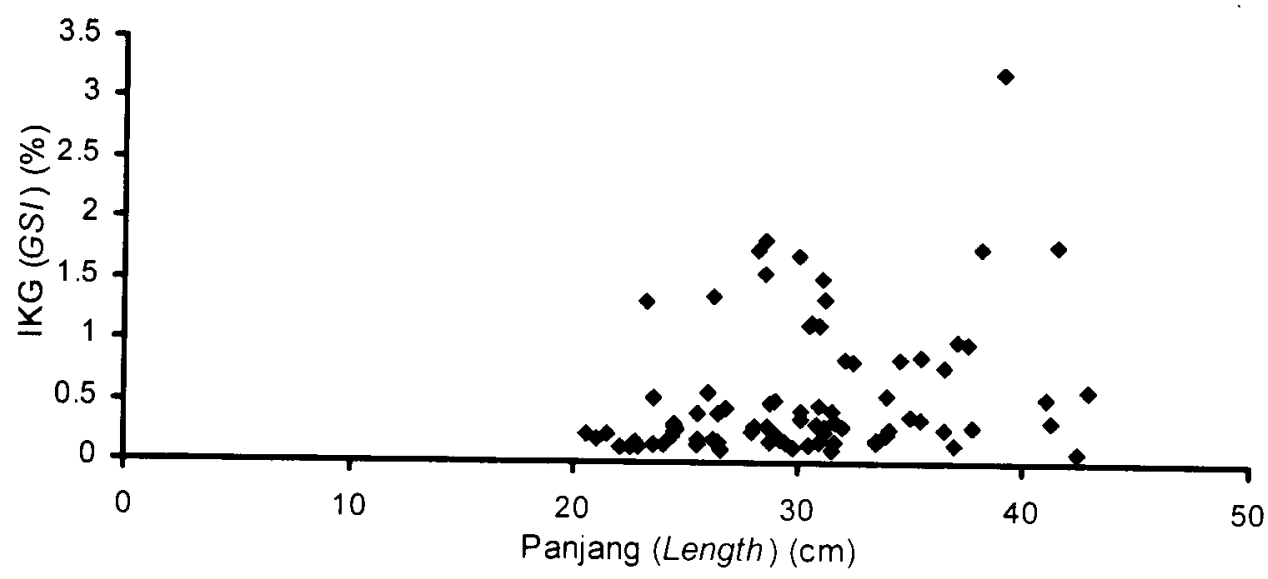

Gambar 4. Hubungan indeks kematangan gonad (IKG) dengan panjang ikan kerapu sunu (Plectropomus leopardus) betina dari perairan Sulawesi dan Maluku

Figure 4. Relationship of gonosomatic Index (GSI) with length of female Plectropomus leopardus from Sulawesi and Maluku waters 
Tabel 2. Ukuran dan jenis kelamin kerapu sunu P. leopardus dari beberapa perairan Sulawesi dan Maluku Table 2. Size and sex of leopard coral grouper P. leopardus from several waters in Sulawesi dan Maluku

\begin{tabular}{|c|c|c|c|c|c|c|c|}
\hline \multirow{2}{*}{$\begin{array}{l}\text { Jenis kelamin } \\
\text { Sex }\end{array}$} & \multirow{2}{*}{$\mathbf{n}$} & \multicolumn{3}{|c|}{$\begin{array}{c}\text { Panjang standar } \\
\text { Standard length }(\mathrm{mm})\end{array}$} & \multicolumn{3}{|c|}{ Berat (Weight) (g) } \\
\hline & & Min & $\operatorname{Max}$ & $\begin{array}{c}\text { Rataan } \\
M \text { ean } \pm \text { SD }\end{array}$ & Min & Max & $\begin{array}{c}\text { Rataan } \\
\text { Mean } \pm \text { SD }\end{array}$ \\
\hline Jantan (Male) & 27 & 185 & 430 & $308.3 \pm 75.54$ & 230 & 2,625 & $1041.48 \pm 689.17$ \\
\hline Betina (Female) & 82 & 205 & 428 & $301.9 \pm 53.41$ & 260 & 2,750 & $902.17 \pm 538.45$ \\
\hline $\begin{array}{l}\text { Hermaprodit } \\
\text { Hermaphrodite }\end{array}$ & 9 & 380 & 437 & $409.3 \pm 16.44$ & 1,600 & 2,500 & $2043.89 \pm 302.08$ \\
\hline $\begin{array}{l}\text { Tak teridentifikasi } \\
\text { Unidentified }\end{array}$ & 3 & 341 & 365 & $354 \pm 12.12$ & 1,025 & 1,500 & $1291.67 \pm 242.81$ \\
\hline & 121 & 185 & 437 & $312.9 \pm 6.33$ & 230 & 2,750 & $1027.83 \pm 629.03$ \\
\hline
\end{tabular}

Tabel 3. Fekunditas ikan kerapu sunu (Plectropomus leopardus) dari perairan Utara Manado (April 2004) dan Gorontalo (September 2004)

Table 3. Fecundity of leopard coralgrouper (Plecropomus leopardus) from North Manado (April 2004) and Gorontalo waters (September 2004)

\begin{tabular}{rrrrr}
\multicolumn{1}{c}{$\begin{array}{c}\text { SL } \\
(\mathbf{c m})\end{array}$} & \multicolumn{1}{c}{$\begin{array}{c}\text { W } \\
(\mathbf{g})\end{array}$} & \multicolumn{1}{c}{$\begin{array}{c}\text { Gonad } \\
(\mathbf{g})\end{array}$} & \multicolumn{1}{l}{$\begin{array}{l}\text { Fekunditas } \\
\text { Fecundity }\end{array}$} & \multicolumn{1}{c}{$\begin{array}{c}\text { Bulan } \\
\text { Month }\end{array}$} \\
\hline 26.2 & 625.0 & 8.519 & 45,786 & April 2004 \\
30.6 & 825.0 & 9.55 & 49,634 & April 2004 \\
37.1 & $1,575.0$ & 15.826 & 53,687 & April 2004 \\
30.9 & $1,100.0$ & 12.357 & 57,396 & April 2004 \\
31.2 & 910.0 & 12.287 & 72,842 & April 2004 \\
28.5 & 780.0 & 12.084 & 74,037 & April 2004 \\
28.5 & 750.0 & 13.845 & 94,467 & April 2004 \\
30.0 & 750.0 & 12.851 & 94,827 & April 2004 \\
38.1 & $1,700.0$ & 30.011 & 100,774 & April 2004 \\
31.1 & 998.0 & 5.07 & 124,524 & April 2004 \\
35.6 & $1,350.0$ & 19.762 & 85,498 & September 2004 \\
39.0 & $1,610.0$ & 52.025 & 492,243 & September 2004 \\
\hline
\end{tabular}

$P$. leopardus mulai matang gonad pada bobot kurang lebih satu kilogram. Bila dibandingkan dengan kelompok fekunditas ikan kerapu sunu yang berasal dari perairan Pulau Karimun Jawa (Andamari et al., 2003) di mana terdapat 2 ekor yang telah matang gonad dengan fekunditas lebih dari 340.000 butir dan 429.000 butir maka fekunditas ikan kerapu pada penelitian ini lebih sedikit jumlahnya kecuali satu ekor lebih banyak jumlahnya (492.243 butir). Diduga hal ini terjadi disebabkan perbedaan umur ikan serta pengaruh musim terhadap kematangan gonad hasil pengamatan reproduksi. Ikan kerapu sunu yang berasal dari perairan Karimun Jawa dan perairan Gorontalo sesuai dengan hasil penelitian Goeden (1978) dalam Heemstra \& Randall (1993) yang menyatakan bahwa jumlah telur kerapu sunu yang berumur 4 tahun berjumlah 457.900 butir.

Dari Tabel 3 terlihat bahwa ikan kerapu sunu terkecil yang mulai matang gonad berukuran $625 \mathrm{~g}$ tetapi baru dalam tahap awal matang gonad dan belum ada yang hidrasi.

\section{KESIMPULAN}

1. Ikan kerapu sunu bersifat hermaprodit protogini.

2. Fekunditas rata-rata berjumlah 112.142 oosit.

3. Kerapu sunu P. leopardus matang gonad mulai dari bobot kurang lebih satu kilogram.

4. Hubungan panjang berat dapat diterima karena nilai 


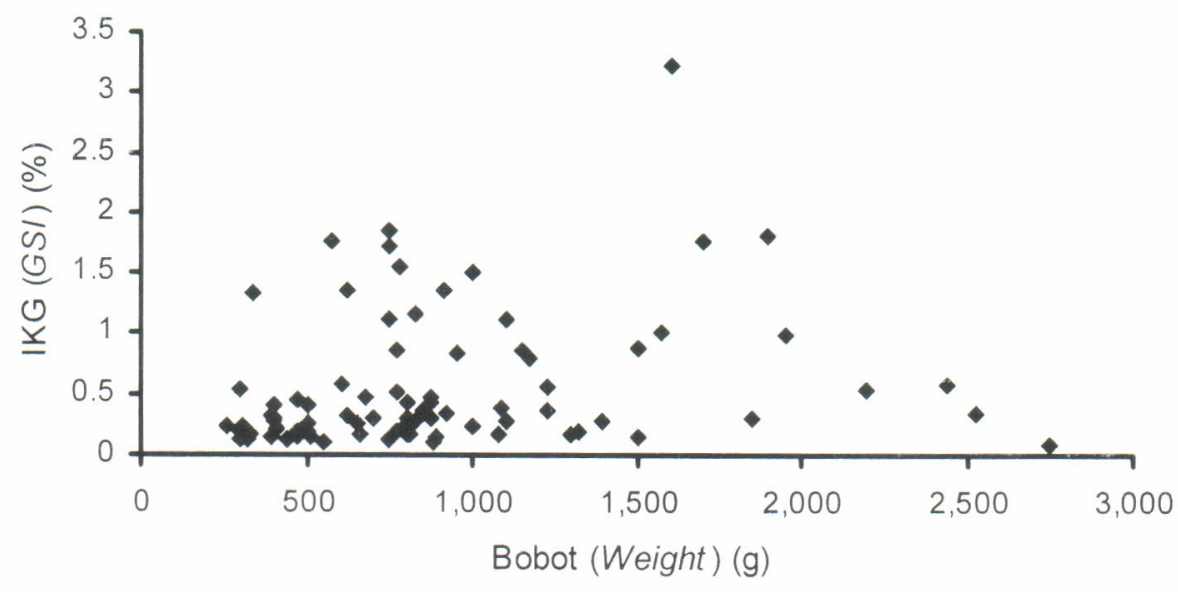

Gambar 5. Hubungan indeks kematangan gonad (IKG) dan bobot ikan kerapu sunu (Plectropomus leopardus) betina dari perairan Sulawesi dan Maluku

Figure 5. Gonado Somatic Index (GSI) and weight relationship of female Plectropomus leopardus from Sulawesi and Maluku. waters

$b=3$ yang berarti ikan kerapu sunu mempunyai pertumbuhan bersifat isometrik.

\section{UCAPAN TERIMA KASIH}

Penulis menyampaikan terima kasih yang sebesar-besarnya kepada Dr. Haryanti dan Ir. Ketut Suwirya, M.S. yang telah memberi kesempatan dan dukungan kepada penulis untuk menyelesaikan tulisan ini, Sdr. Mujimin yang telah menyiapkan preparat histologi, dan Sdr. B. Teguh Trihandoyo yang membantu dalam penyiapan konsep

\section{DAFTAR PUSTAKA}

Andamari, R., M. Farmer, U. Chodriyah, and A. N. Susanto 1998. Gonad maturity stages of anchovies (Encrascholina heterolobus) from Bacan Island. Indonesian Fisheries Research Journal, IV (2):47-51.

Andamari, R., S.B. Moria, I G.N. Permana, Haryanti, dan K. Suwirya. 2003. Bioreproduksi dan Karakteristik Variasi Genetik Ikan Kerapu Sunu (Plectropomus leopardus). Makalah dipresentasikan pada Seminar Pembahasan Hasil Penelitian Tahun 2003 di Singaraja. Hotel Bali Taman, 3-4 Desember 2003.

Andamari, R., Haryanti, dan K. Suwirya. 2004. Aspek Reproduksi Ikan Kerapu Sunu (Plectropomus leopardus). Prosiding Peranan Biosistematika dalam Menunjang Pemanfaatan Keanekaragaman Hayati. ITS. Surabaya, 25 September 2004

Andamari, R., S.B. Moria, and I G.N. Permana. 2005. Aspect of reproduction in the leopard coral grouper
(Plectropomus leopardus) from Indonesia. Paper will presented in World Aquaculture Society, Bali 9-14 may 2005

Anonymous. 2004. Data Ekspor Hasil Perikanan Propinsi Bali Tahun 2001. Lab. PPMHAP, Propinsi Bali bekerja sama dengan Pusat Riset Perikanann Tangkap. Denpasar 2004

Bagenal, T. B. 1978. Methods for Assessment of Fish Production in fresh Water. IBP. Handbook (3) Blackwell Scientific Publications, Oxford, 253 pp.

Chou and Lee. 1998. Commercial marine fish farming in Singapore. Aquaculture Research, 10: 767-777.

Cyrus, D.P. and S.J.M. Blaber. 1984. The reproductive biology of Gerres (Teleostei) Bleeker 1859, in Natal estuaries. J. Fish. Biol., 24: 491--504.

Effendie, M. I. 1997. Biologi Perikanan. Yayasan Pustaka Nusantara. Jogjakarta.

Goeden, G.B. 1978. A monograph of the coral trout, Plectropomus leopardus (Lacepede). Queensland Fish. Serv. Res. Bull., (1): 1-42

Heemstra, P.C. and J.E. Randall. 1993. Groupers of the World. FAO Species Catalogue Vol. 16. FAO Fisheries Synopsis, 16 (125): $382 \mathrm{pp}$

Hunter, J.R. and S.R. Goldberg. 1980. Spawning incidence and batch fecundity in northern anchovy Engraulis mordax. Fish. Bull. U.S., 77: 641-652.

Luna, L.G. 1968. Manual of Histological Staining Methods of the Armed Forces. Institute of Pathology. 3 rd. ed. McGraw-Hill, N.Y.

Royce, W.F. 1984. Introduction to the Practice of Fishery Science. Academic Press. California, USA, $423 \mathrm{pp}$. 